\title{
A BPMN-based process map for the design and construction of façades
}

\author{
Eleanor Voss ${ }^{\mathrm{a}, *}$, Qian $\mathrm{Jin}^{\mathrm{b}}$ and Mauro Overend ${ }^{\mathrm{b}}$ \\ ${ }^{a}$ Glass and Façade Technology Research Group, Department of Engineering, University of Cambridge, \\ Cambridge, UK \\ ${ }^{\mathrm{b}}$ Glass and Façade Technology Research Group, University of Cambridge, Cambridge, UK
}

Received: 12 August 2013

Accepted: 20 November 2013

\begin{abstract}
Process mapping can lead to significant efficiency and quality improvements in construction engineering and is an ideal basis for developing IT support tools. The increasing complexity and multidisciplinary nature of façade design and construction suggest that a process map would be beneficial in this sector of the construction industry, but it has received limited attention to date. This paper presents a verified process map of the façade design and construction process. The map is the first of its kind to represent, in detail, the whole process relevant to all façade types, from commencement of the façade consultant's and contactor's participation, to the end of their involvement. The paper describes the process by which the mapping notation was selected, followed by the development and verification of the process map, including testing in two independent research projects. The BuildingSMART's BPMN notation is found to have superior system features and comprehensibility for this application and the resulting process map is easy to interpret and verify by industry experts. The trialling of the map in the two research projects indicate that the map is a useful tool for assessing process improvements in the façades sector.
\end{abstract}

Keywords: Process map, façade design process, project management

\section{Introduction}

Façade design and construction is a relatively new sector of the construction industry, as is the role of the professional façade engineer (Karsai, 1997). The sector is complex in terms of the range of materials employed, geometries involved, performance requirements and its collaborative multidisciplinary nature. These conditions suggest that a process map would be a very useful aid to researchers in this field.

\subsection{The benefits of process mapping}

The main benefits of process mapping include: increasing understanding of actor's roles and activities (Klotz et al., 2008); aiding identification of strategic, process and IT requirements (Aouad et al., 1999); or forming the basis for IT systems (Tzortzopoulos et al., 2005).

Mapping the 'as-is' situation in the planning, design and construction of sustainable buildings, increases the understanding of the process by $5-27 \%$ and leads to efficiency and quality improvements

\footnotetext{
${ }^{*}$ Corresponding author: Eleanor Voss, Glass and Façade Technology Research Group, Department of Engineering, University of Cambridge, Trumpington Street, Cambridge, UK. E-mail: ev236@cam.ac.uk.
}

ISSN 2213-302X/13/\$27.50 @ 2013 - IOS Press and the authors. All rights reserved

This article is published online with Open Access and distributed under the terms of the Creative Commons Attribution Non-Commercial License. 
Klotz et al. (2008). This agrees with the findings of Tzortzopoulos et al. (2005), whose list of benefits to the construction industry includes supporting education and development of IT systems.

\subsection{Process mapping in the façades sector}

There has been limited mapping of the façade design and construction process. Much of what does exist focuses on specific façade typologies or provides a low level of detail. However, some of the work conducted to date has been used to develop the map presented in this paper.

Klein (2013) produced a high-level map showing the current involvement of stakeholders during different project stages and a set of maps showing a revised process for a new approach to façade design. In addition, a hierarchical set of façade design and construction process maps were developed in the CladdISS project (Pavitt \& Gibb, 2003) by eliciting knowledge from industry through interviews and questionnaires (Pavitt \& Gibb, 1999). These maps are presented in a tabulated format and capture the key stages, decisions and management issues related to the interface between the façade and other building components. In both research projects the maps fulfil the purpose for which they were intended, but they either work to a very high level of abstraction (and low level of detail) or describe an ideal (or proposed) process.

Pavitt's and Gibb's work formed the basis of a set of maps developed subsequently by Vaz et al. (2008). The maps use the Integration Definition for Function Modelling (IDEFO) notation and were produced to improve the understanding of the façade design process and to identify façade-structure interface issues. These maps mainly provide a high-level overview of the façade design and construction process, showing the main project stages. However, a more detailed map focusing only on the design of the façadestructure interface was also developed. In addition, the IDEFO notation used by Vaz et al. is significantly clearer than the tabulated format used in the CladdISS project. It is therefore evident that the choice of mapping notation should be considered carefully as it affects comprehensibility.

The IDEFO notation was also used in the CIMclad project to map the design-to-installation processes of rainscreen cladding (Agbasi et al., 2003). The map is constructed from the perspective of consulting façade engineers and it was used for the development of a rainscreen cladding product model. Although the process is mapped to a high level of detail, the work focuses on a single type of cladding.

There are also several research projects on the mapping of the precast concrete cladding sector. Karhu (1997) worked on mapping the precast cladding process in order to develop a product data model using the IDEFO notation. Gray and Al-Bizri (2007) proposed a knowledge-based-engineering (KBE) representation of design processes and illustrated the concept with a map of the precast cladding design process. The maps were intended to clarify the roles and responsibilities of the designer. Finally, Eastman et al. (2003) have developed several maps, using different notations, of the architectural precast design and fabrication processes. This body of work provides significant levels of detail, but the maps are limited to precast concrete cladding.

\subsection{Process map production}

\subsubsection{Mapping notations}

The IDEFO mapping notation has been used in several processes mapping research projects, both in the façades sector (Kalian et al., 1997; Vaz et al., 2008) and the wider construction industry (Laitinen, 1999; Dawood, 2002; Pingtserng, 2004). The IDEF0 is a function modelling notation and is the standard initial step in the ISO-STEP methodology (Eastman et al., 2002). It aims to capture decisions, actions, 
and activities of an organization or system. The notation comprises of hierarchical diagrams using 'box and arrow' graphics, the box representing functions and the arrows represent inputs, outputs, controls and mechanisms (IDEF, 2010).

An alternative notation is the Business Process Modelling Notation (BPMN) which is used by BuildingSMART to develop the IFCs (International Foundation Classes). The notation is based on a flowchart technique with graphical objects representing activities and flow controls describing their sequence. Hierarchical modelling is supported through a plus sign indicating expansion in the activity object (Wix \& Karlshoj, 2010). A range of BPMN concepts are expressed in IFC-compatible format, for example, a swimlane, or zone of the map where the activities relating to a single professional role are placed, is represented by ifcActorRole (Wix \& Karlshoj, 2010).

Several process maps are now available through the BuildingSmart website (BuildingSmart, 2008), some of which include parts of the façade design process, for example, the 'Architectural Design to Building Energy Analysis' map. In addition, Eastman et al. (2010) have developed a process map of the precast façade design process using the BuildingSMART - BPM notation.

Two main knowledge elicitation methods are frequently used in the development of these process maps: (1) An initial literature review to gather information about the design and construction process (Kagioglou et al., 2000; Gray \& Al-Bizri, 2007), followed by; (2) an evaluation by industry members, through workshops or case studies, to either produce or enhance the map (Aouad et al., 1999; Kalian et al., 2004; Gray \& Al-Bizri, 2007). Once completed, the accuracy of a process map may be quantified by means of interviews in which real-world case studies are compared with the original map (Austin et al., 1999).

\subsubsection{Evaluation of mapping notations}

Alternative mapping approaches may be analysed by means of the structure provided by Kochikar and Narendran (1994), who distinguished between modelling power and decision power, where: modelling power is the universe of system features that a notation can represent, and; decision power is the ease with which a map can be analysed. The features of each of these two characteristics are summarised by Koskela (p.g. 506, 1995). The IDEF notation has been reviewed in several research projects (Karhu, 2001; Eastman et al., 2002; Wynn, 2007), however, there is a lack of publications on evaluations of the BuildingSMART-BPM notation.

\subsection{Scope of the paper and content to follow}

At present, there is no detailed façade design and construction process map that is applicable to all façade types. Such a map would be useful for identifying and quantifying possible improvements to the façade design and construction process. For example, in the development of software applications that support façade designers/fabricators without disrupting the existing processes, or in assessing the impact of a new procurement system. Therefore this paper presents a verified process map of the façade design and construction process from initial design to completion for use as a research resource. In Section 2, the two principal mapping notations (BPM-BuildingSMART and IDEFO) are evaluated and a preferred notation is selected. This is followed by a description of the iterative interview-approach used to develop the map, a description of the map itself, and a qualitative evaluation of its accuracy. The value of the map as a resource for further research and development in the façade industry is demonstrated in Section 3. Finally, Section 4 presents conclusions and areas of further work. 
Table 1

Comparison of IDEFO and BPMN-BuildingSMART notations

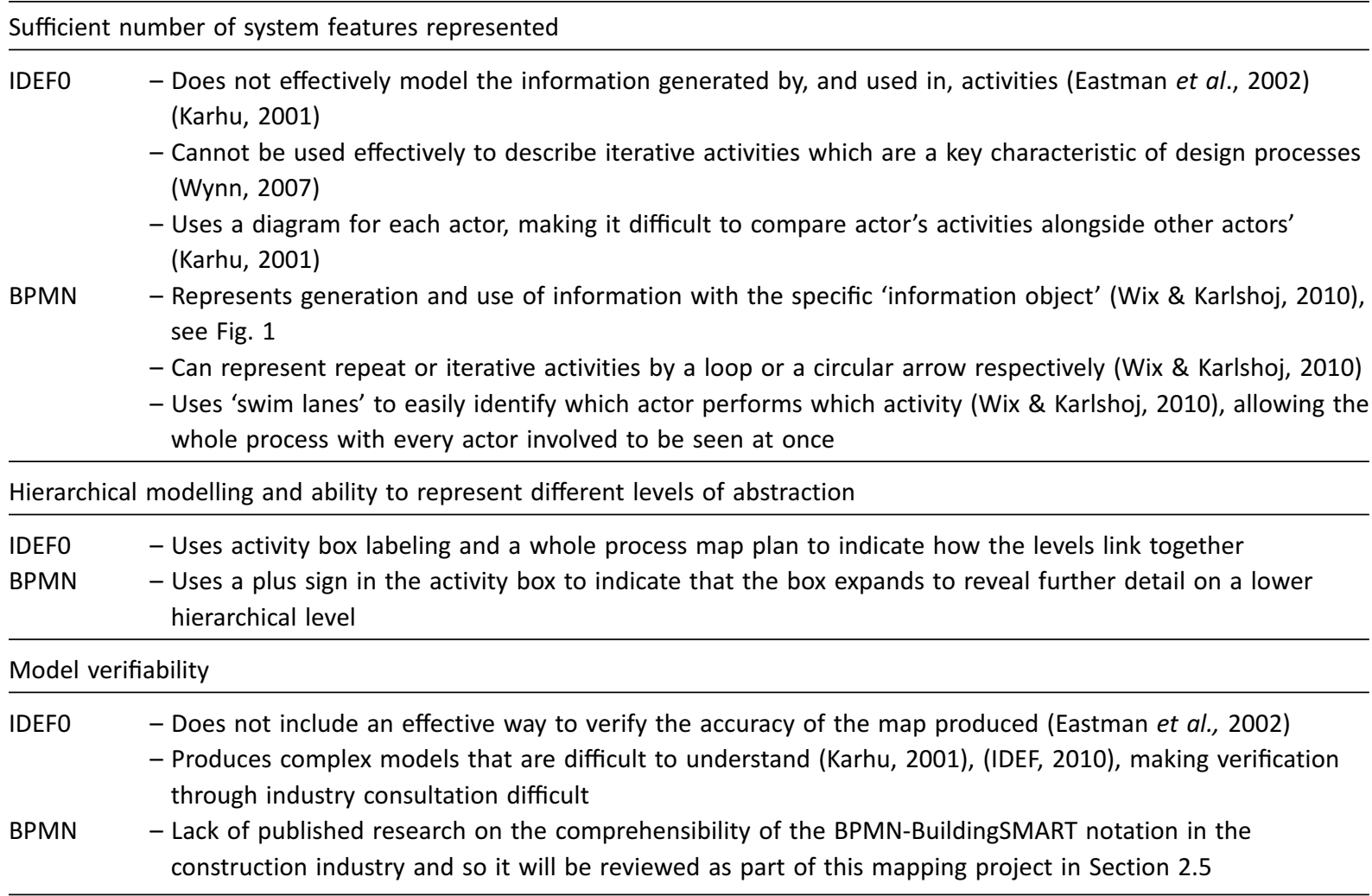
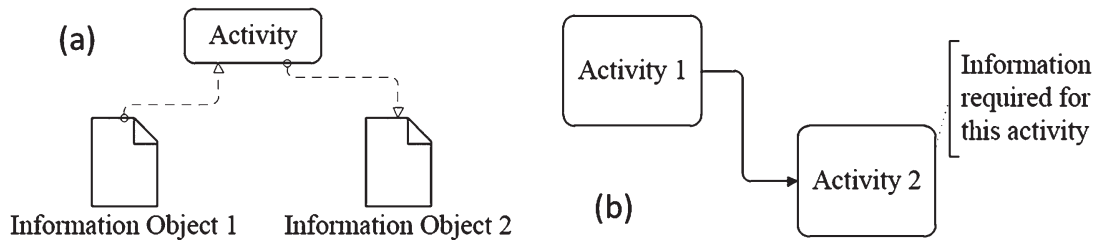

Fig. 1. Example of (a) BPM notation and showing an activity and two information objects and (b) IDEFO notation showing two activities and an information annotation.

\section{Production of the process map}

\subsection{Selection of mapping notation}

BuildingSMART's adaptation of the BPMN is a strong candidate for the façade process map, as it supports an exchange schema (BuildingSMART IFC) that is particularly suitable for the development of computer based support tools. However, this modelling notation has not been used previously for 
façade design process mapping. It is therefore sensible to evaluate it against the IDEFO notation which is a recognised modelling standard (by American National Institute for Standards and Technology) and which has frequently been used for process mapping research projects.

The comparison presented in Table 1 evaluates these two mapping notations against each other by considering each of Koskela's (1995) characteristics of modelling methods, however since the primary purpose of this map is modelling power, the evaluation disregarded, but did not penalise poor decision power. The accuracy of the whole façade design and construction process map presented in this paper has been verified through interview based consultation with industry, hence it is essential that the maps are understood with ease so that errors and omissions can be identified. Therefore comprehensibility is used to assess Model Verifiability. In addition, the purpose of this mapping project is to produce an 'as-is' representation of the current process, rather than any changes to it. Therefore the criterion that the notation should be able to represent evolution of processes is neglected at this stage.

\subsubsection{Conclusions on mapping notations}

From this evaluation it is evident that the BuildingSMART BPMN adaptation is at least as suitable as the IDEFO notation for the production of a whole façade design and construction process map, and in some criteria, the BuildingSMART BPMN out-performs IDFEO. The areas where the IDEFO notation under-performs in the context of this mapping project are: (1) available representation system features (particularly iterative activities and allocation of activities between industry professions), and; (2) model verifiability through review, which requires comprehensibility. Hence, the BPMN-BuildingSMART modelling notation was selected.

\subsection{The process map development method}

Following initial consultation with the potential interviewees the following five step method was developed and employed:

1. Relevant information from existing façade-related process maps was extracted. The most relevant work was the CIMclad process maps (Kalian et al., 2004). The IDEFO notation employed in the original map was difficult to understand (see Section 2.1.3), therefore, the maps were reformatted in the BPM-BuildingSMART notation. The maps produced by the CladdISS project (Pavitt \& Gibb, 2003) were not used further in this project as they represent the ideal rather than the 'as-is' activities and information exchanges.

2. Further knowledge was elicited from industry to ensure the map represented the design and construction process for all façade typologies. This started with the production of a highly simplified process map followed by interviews with selected industry experts. The interviewees were asked to work through the process map, adding information and making corrections. Four interviews were conducted, two with façade sub-contractors and two with façade consultants.

3. The two sources of information (from step 1 and 2) were merged to form the version 1.0 of the process map using the BPMN-BuildingSMART notation. When combining the information from the interviews, no judgement was made as to the relative authority or accuracy of different sources, instead leaving this to the later steps of review (step 4) and accuracy verification (step 5). Any process map element that was specified by any source was included, while clashes 
Table 2

Results of map validation in step 5 interviews. (Total number of map elements $=169$ )

\begin{tabular}{lcccc}
\hline Interview & (a) Missing & (b) Redundant & (c) Modified & (d) Accuracy (\%) \\
\hline$\# 1$ & 16 & 5 & 5 & 88 \\
$\# 2$ & 24 & 27 & 11 & 79 \\
$\# 3$ & 12 & 31 & 9 & 86 \\
$\# 4$ & 14 & 5 & 10 & 87 \\
Average & 17 & 17 & 9 & 85 \\
\hline
\end{tabular}

in sequencing were resolved by representing these steps as 'potentially concurrent' on the map.

4. The map was reviewed by industry experts using a workshop format and the suggested modifications were incorporated. The workshop participants consisted of three façade consultants from a single firm. The revised process map (v1.1) consisted of a total of 169 elements.

5. The revised map (v1.1) was verified by a further set of four interviews with industry experts using a case study format. The interviews were conducted with four different façade consultants, none of whom had been involved in the previous steps of the mapping process. During each of these interviews, the map was compared to the process undertaken in a recent real-world façade design projects and inaccuracies and omissions were recorded (Table 2). Each façade project had a construction cost of over $£ 15 \mathrm{M}$ and was either completed in 2012 or later. Three categories of inaccuracies were identified: (a) missing, which represent the process elements that were needed to capture the project but were not in the map; (b) redundant, which represent those elements that should be removed from the map to make it reflect the real project; (c) modified elements indicating process elements that required minor modification to conform to the process undertaken on the real project. From these the accuracy, of the map which quantifies the overall ability of the process map to represent each project, therefore accuracy $d=[(169-b-c)) /(169+a-b)]^{*} 100 \%$.

\subsection{The process map}

The process map is large, therefore only extracts are reproduced in this paper. The full map (v1.1) is available through the Glass and Façade Technology Research Group website (gFT, 2012), where it is possible to navigate electronically through the map hierarchy using hyperlinks. Two extracts have been selected to show a range of detail. Figure 2 shows the top level map that summarises the whole façade design and construction process and an expanded portion of activity A5.

The top level map (Fig. 2a) illustrates the whole project process, ends of key stages are identified through double lined circles, and the whole process end is indicated by a bold lined circle. The map shows the façade consultant's activities in the top swimlane and the facade contractor's process step in the bottom swimlane. The plus signs at the base of each activity indicate that further detail on this activity is available and can be accessed by the user.

The expansion of the main activities (Fig. 2b) includes details of the information used and produced in each sub-activity. For example, the construction information comments are generated by activity A5.3 Review of construction information including coordination with other systems. 
(a)

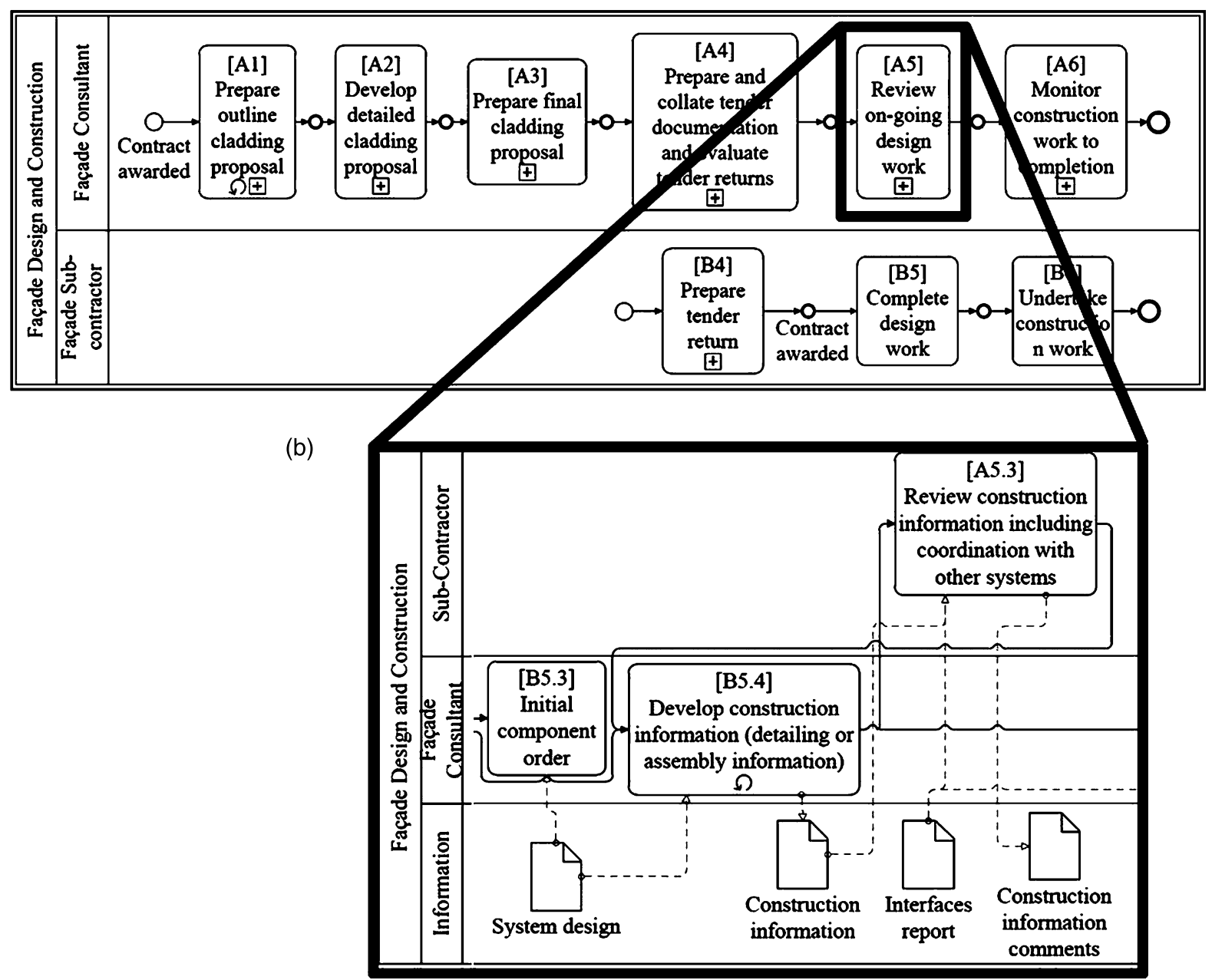

Fig. 2. Map v1.1 (a) Top level map and (b) portion of activity A5 expanded.

\subsection{Evaluation of process map and notation}

The accuracy verification step identified some errors in the map. However, the majority of the map accurately represented the real projects used in the verification interviews (step 5) interviews. On average v1.1 of the map was $85 \%$ successful in capturing the real-world project. It was noted that the same inaccuracies were identified in more than one interview, for example, the construction and review of visual and performance mock-ups had not been included in the map of step 5 . All four interviews identified these as 'missing'.

Although further development and improvement of the map is underway, the validation by means of independent interviews indicates that the map provides a reasonably accurate representation of the façade design and construction process. 
During the interviews and workshops the industry experts were able to quickly interpret the map, indicating the notation is easily understood, and the industry processes were represented with ease, indicating that the notation has a sufficient number of system features. This practical evaluation confirmed that the BPMN-BuildingSmart notation was suitable for the mapping project, particularly with regards to the ability of mapping non-experts to interpret the map.

\section{Use of process map in research projects}

A process map, such as the one presented in this paper, is particularly useful for assessing whether the outcomes of a research project are compatible with current industry processes (incremental /evolutionary innovation) or whether it would be beneficial to alter the current industry processes in order to exploit the benefits of the research (revolutionary / disruptive innovation). The BMPN Façade Process Map was deployed in two on-going research case studies, and the contributions of the map to the research projects are identified and discussed in this section.

\subsection{Research case study 1}

The Knowledge-Based Façade Design Development (KBFDD) research project aims to improve communication between construction industry domains thereby improving the process of designing, construction and operation of façades. The objective of the research project is to develop a prototype Building envelope Information Model (BeIM) tool that supports the façade consultant - and indirectly the design team - as they devise the panelisation scheme of façades. The BeIM tool encourages the users to generate design options that are feasible and cost effective to manufacture by increasing the users understanding of the effects of downstream design constraints. The project uses a construction industry neutral BIM digital format to improve communication of design information between members of the design team (Voss \& Overend, 2012).

The process map described in Section 2 played three key roles in the research project: Firstly, the process map described in this paper provided the researcher with an overview of the façade industry, placing the project in context. The map was used as graphical summary of the actors, information exchanges, and roles in the sector.

Secondly, the map was used to identify patterns of use of specific information objects. For example, by identifying the repeated use of information objects that are not project-specific, a system can be developed to capture, store, and make accessible these elements of information for re-use in subsequent projects. In addition, by assessing when these information objects are used, the BelM tool has been developed to encourage users to update the recycled information. For example, activity A1.5.1 (shown in Fig. 3) requires knowledge of size restrictions on façade panels to assess the panelisation scheme proposed by the project architect. This information is owned by the consultant and not specific to the project. The same information is used again for activity A1.5.2, a development rather than a review task. The information stored by the consultant can be updated during activity A4.6.1 when the same type of information, this time owned by the contractor, but communicated to the consultant, is used to review the design.

Finally, the map provided the resource necessary to develop a tool that could be deployed in industry without disrupting the current process i.e. the tool will support and not hinder current practice. For example, the map enabled the researcher to ensure that the information required by the tool will be available at the stages in the design process that the tool is to be used. The BelM tool can be 


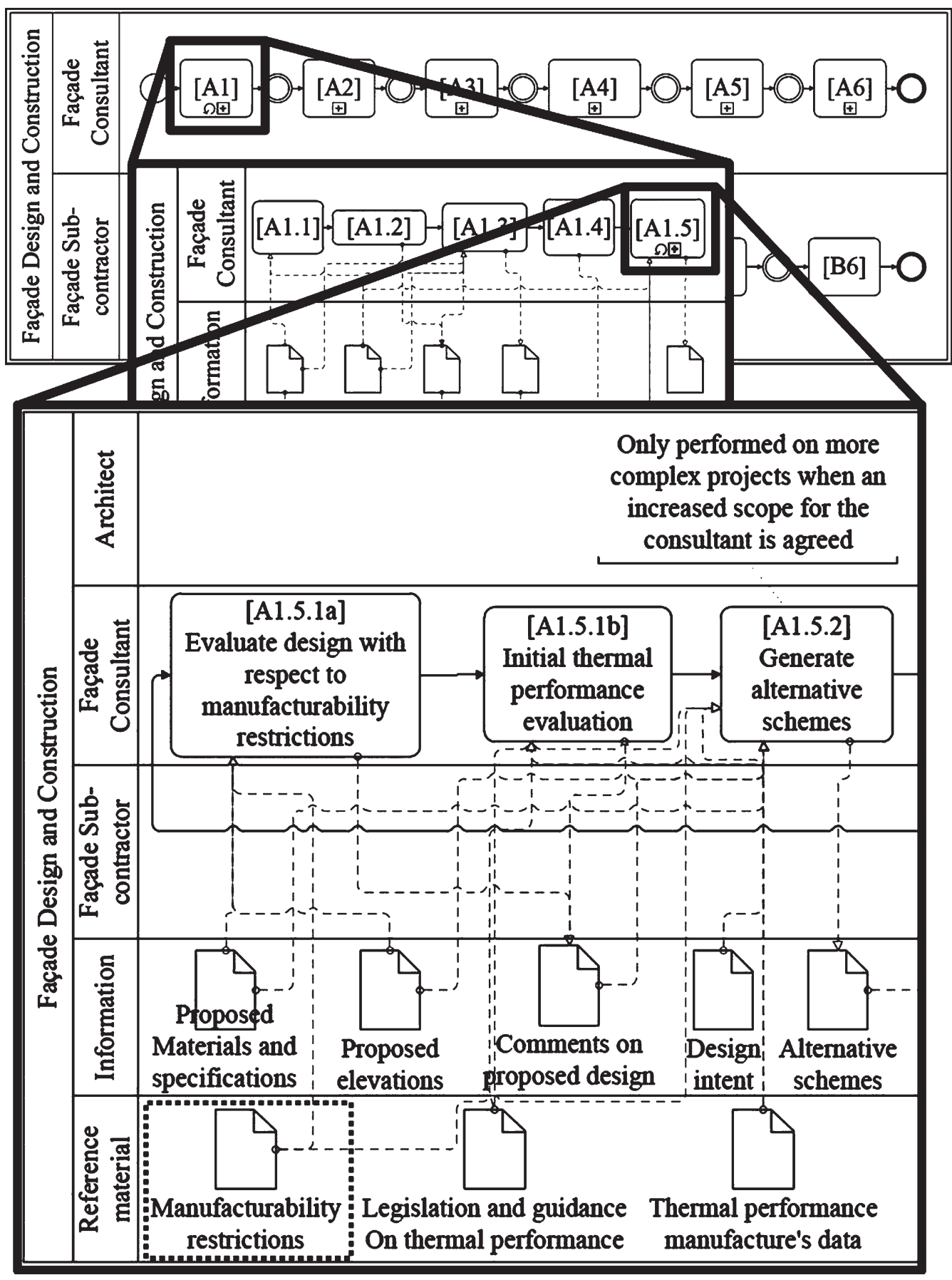

Fig. 3. Map v1.1, Portion of activity A1.5 expanded to show sub-activities A1.5.1a, A1.5.1b and A1.5.2 and the information required and produced during these activities. 
employed from activity A1.5, when the consultant has the Appointment Brief which documents the proposed panelisation scheme for the consultant to review. However, it is clear that the panelisation scheme becomes more detailed during the design phases so the BelM tool must be able to handle a range of levels of scheme detail.

\subsection{Research case study 2}

The second case study used the process map to develop a whole-life value (WLV) based facade design and optimisation tool. The optimisation tool is developed for early design stage. It is accounts for the three major design objective values: (a) functional value (indoor environment quality, structural serviceability and safety, and durability); (b) financial value (initial capital cost, operating cost, replacement cost, and disposal cost); (c) environmental sustainability value (resources consumption and emission to ecosystem). The evaluation of the three objective values is performed using a simulation engine consisting of 3rd party software and specially developed MATLAB scripts. This optimisation tool is still under-development, and some preliminary results can be found in Jin et al. $(2011,2013)$.

The BPMN Façade Process Map was used: (1) to assess whether the design optimisation tool is compatible with the current façade design process, i.e. whether the information available at early façade design stage is sufficient to run the design optimisation tool and whether the outputs from the design optimisation tool provide sufficient information for the subsequent design stages, and; (2) to identify how the current façade design process captured in the process maps could be modified to make better use of the design optimisation tool. The 'Façade Consultant' swim lane encompassing activity $A 2$ and activity $A 3$ (Fig. 2 ) is relevant in this case.

According to activity A2 (shown in Fig. 4) of the process map, the thermal performance criteria (e.g., $U$-value and $g$-value) are provided by the building services engineers for activity A2.X when initial thermal performance calculations are carried out by façade consultants to identify façade options that satisfy these criteria. This map shows that this activity is iterated until the proposed design satisfies the requirements set by both building services engineers and façade consultants. The building energy simulation module in the design optimisation tool can be deployed here, however, it performs a multiobjective optimisation i.e. the two tasks performed by the building services engineers and the façade consultants are considered simultaneously rather than separately. The process map indicates that all other input variables and constraints required for the optimisation tool (e.g. building geometry, location, orientation, plant size and plant type will be available at this stage from the RIBA (Royal Institute of British Architects) Stage $C$ report. The output from the optimisation tool will also be timely as it can be included in the RIBA Stage D report. Therefore, the WLV façade design optimisation tool is partly compatible with the current design process and the process map successfully identified a problem that would arise when using the optimisation on real-world projects unless changes are made to the optimisation tool or to the current design process.

A similar process was undertaken to assess the compatibility of the optimisation tool with the Structural analysis (activity A3.1) and detailed thermal analysis (activity A3.2), but are not reported in detail here for brevity. This showed that the inputs and outputs for the design optimisation tool are compatible with the current design process.

\section{Conclusions and further work}

This work included a theoretical and a practical evaluation of two candidate process mapping notations from which BuildingSMART-Business Process Mapping Notation emerged as the more suitable 


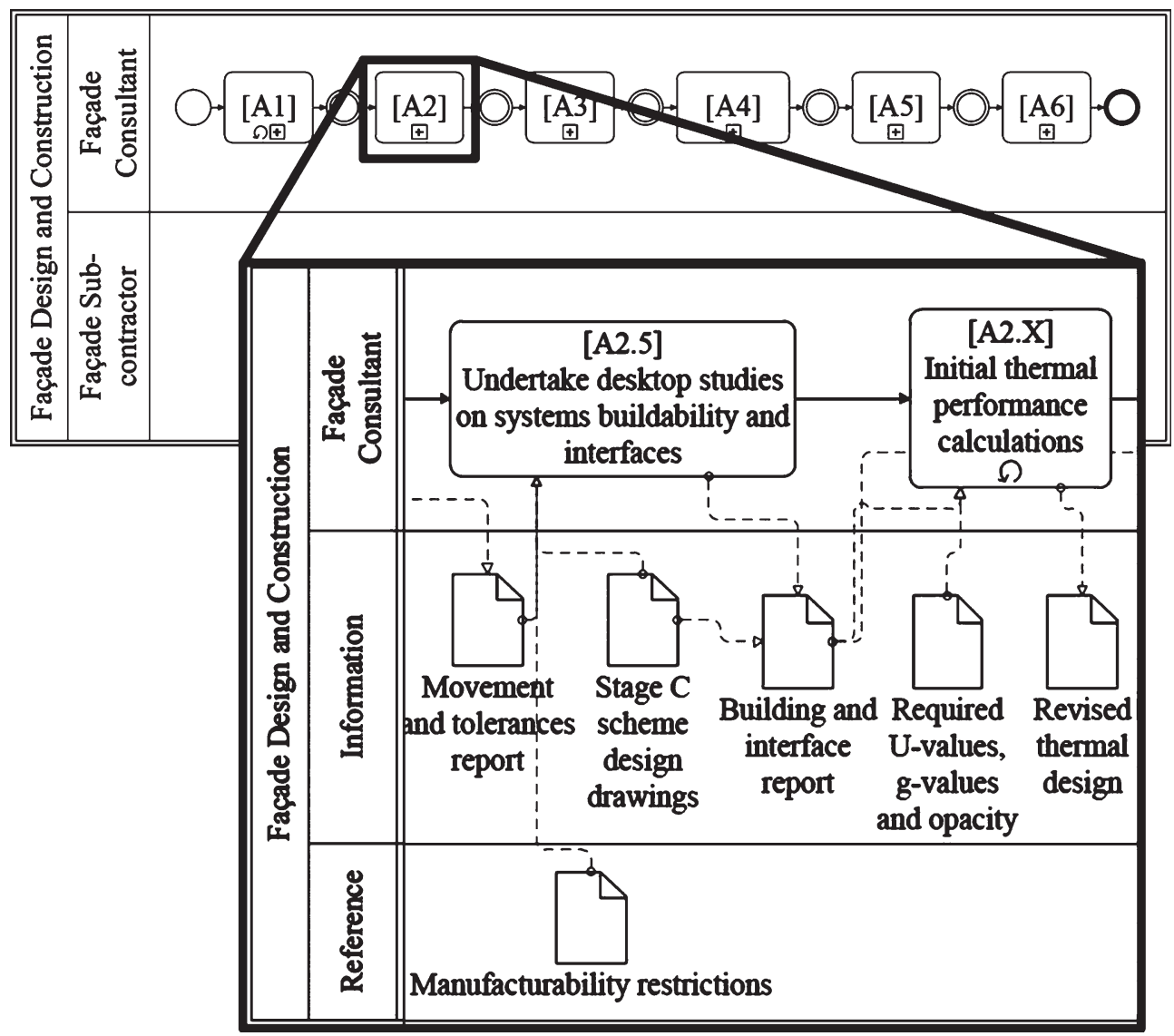

Fig. 4. Map v1.1, Portion of Activity A2 expanded showing the information required and produced during Initial Thermal Performance Calculations.

notation for the façades sector. The theoretical evaluation, using the characteristics of modelling notations, indicated that the BPMN was more suitable than the IDEFO notation to model the façade design and construction process. The practical evaluation, through use of the process map in interviews with construction industry members, concludes that the notation can represent a sufficient number of system features, and is sufficient comprehensible to enable rapid verification through industry consultation.

This paper also presented the first ever detailed BPMN-based process map of the whole facade design-construction process from commencement of façade consultant and contractor participation to the end of their involvement. This map combines previous mapping efforts and recent developments in this sector elicited from industry. The map is intended as a research tool that captures existing construction practices thereby providing the research community with an increased understanding of the construction industry and a basis for the development of design theories. The full map v1.1 is freely available to view through the gFT website (gFT, 2012).

On average version 1.1 of the map successfully captured $85 \%$ of the processes undertaken in each of the four real façade projects used in the verification step interviews. However, the sample size is likely to be too small to make significant further generalisations. The verification step identified 
some inaccuracies in the map that are being addressed at the time of writing to produce version v1.2, however, further testing will be required to verify the modifications. In addition, the map is limited by the sample size in both the map construction and map verification steps. In particular, the verification step (step 5), was limited to participants from façade consulting firms and none from contracting firms. This is likely to cause the design stages of the map to be more detailed and accurate than the construction stages. Furthermore, the map has been produced from the perspective of the façade consultant and façade sub-contractor roles. This limits the map's documentation of interaction of the core façade design and construction team with other project roles, for example the structural engineer. Both of these issues could be addressed through further development work, but currently this is not planned. Finally, the selection process for the notation deliberately neglected ability to represent process evolution. Therefore if the map is used in future research to consider ongoing modifications of processes, further work would be required to verify the suitability of the notation.

The process map was successfully trialled in two independent research projects that involve the development of knowledge-based systems for the facades sector. The map was found to be very useful for assessing the interaction between the proposed knowledge-based system and the current façade design-construction processes. The process map was successfully used in case study one to detect the presence of non-project specific actor knowledge throughout the design process, thereby assessing whether Knowledge Based technologies would be effective. The process map was used successfully in the second case study to verify the availability of information required for the proposed design optimisation tool. In this latter case, the use of the process map highlighted a shortcoming in the current division of scope and responsibility between designers that may inhibit façade design optimisation.

\section{Acknowledgments}

Thanks are due to Focchi Ltd, Permasteelisa UK Ltd, and the Façade Team at Ramboll UK Ltd for their input into the map construction phases. Additional thanks are due to WSP Group, Arup, Newtechnic and Wintech for their contribution to the map verification phase. We would also like to acknowledge Ramboll UK Ltd and the EPSRC for funding this research project.

\section{References}

Agbasi, E., Mcwilliams, R., Stevens, W., Stapleton, J., Anumba, C. J., \& Gibb, A. (2003). CIMclad, RAIS Report, Organisational-level issues bearing on CIM implementation: Facade Engineer's Perspectives. Whitby Bird and Partners Report.

Aouad, G., Cooper, R., Kagioglou, M., \& Sexton, M. (1999). The development of a process map for the construction sector. In CIB Working Groups W65/W55. South Africa.

Austin, S., Baldwin, A., Li, B., \& Waskett, P. (1999). Analytical design planning technique: A model of the detailed building design process. Design Studies, 20(3), 279-296.

BuildingSmart. (2008). Information Delivery Manual - Overview. Retrieved July 25, 2010, from http://iug.buildingsmart.com/idms/overview

Dawood, N. (2002). Development of automated communication of system for managing site information using internet technology. Automation in Construction, 11(5), 557-572. doi:10.1016/S0926-5805(01)00066-8

Eastman, C., Lee, G., \& Sacks, R. (2002). A New Formal and Analytical Approach to Modeling Engineering Project Information Processes. In CIB W78 (pp. 125-132), Aarhus, Denmark.

Eastman, C. M., Jeong, Y.-S., Sacks, R., \& Kaner, I. (2010). Exchange Model and Exchange Object Concepts for Implementation of National BIM Standards. Journal of Computing in Civil Engineering, 24(1), 25. doi:10.1061/(ASCE)0887-3801(2010)24:1(25)

Eastman, C., Sacks, R., \& Lee, G. (2003). Development and implementation of advanced IT in the North American precast concrete industry. Precast Concrete, 1-16. 
gFT (2012). Glass and facade technology research group. Retrieved from www.gft.eu.com

Gray, C., \& Al-Bizri, S. (2007). Modelling trade contractor information production. Architectural Engineering and Design Management, 3(1), $39-48$.

IDEF (2010). www.idef.com. Retrieved September 22, 2011, from www.idef.com

Jin, Q., Overend, M., \& Thompson, P. (2011). A whole-life value assessment and optimisation model for high-performance glazed facades. In Proceedings of International conference of Building Simulation, Sydney, Australia.

Jin, Q., \& Overend, M. (2013). A prototype whole-life value optimization tool for facade design. Journal of Building Performance Simulation. doi:10.1080/19401493.2013.812145

Kagioglou, M., Cooper, R., Aouad, G., \& Sexton, M. (2000). Rethinking construction: The generic design and construction process protocol. Engineering Construction and Architectural Management, 7(2), 141-153. doi:10.1046/j.1365-232X.2000.00148.x

Kalian, A., Watson, A., Agbasi, E., Anumba, C., \& Gibb, A. (2004). Modelling the building cladding attainment processes. Business Process Management Journal, 10(6), 712-723.

Karhu, V. (1997). Product Model Based Design of Precast Facades, Royal Institute of Technology, Stockholm, Sweden.

Karhu, V. (2001). A generic construction process modelling method, Royal Institute of Technology, Stockholm, Sweden.

Karsai, P. (1997). Facade Procurement: The role of the facade consultant. In ICBEST '97, Bath, UK.

Klein, T. (2013). Integral Facade Construction. Rotterdam: Design: Sirene Ontwerpers. doi: http://dx.doi.org/10.7480/a\%2Bbe.vol3.diss3

Klotz, L., Horman, M., Bi, H. H., \& Bechtel, J. (2008). The impact of process mapping on transparency. International Journal of Productivity and Performance Management, 57(8), 623-636.

Kochikar, V. P., \& Narendran, T. T. (1994). On using abstract models for analysis of flexible manufacturing systems. International Journal of Production Research, 32(10), 2303-2322. doi:10.1080/00207549408957069

Koskela, L. (1995). On foundations of construction process modelling. In CIB Workshop on Computers and Information in Construction. Stanford, California.

Laitinen. (1999). Model based construction process management. Durability of Building Materials and Components, 8, $2844-2863$.

Pavitt, T. C., \& Gibb, A. G. F. (1999). Managing organizational interfaces in the cladding supply chain: Initial Results From Expert Interviews. In W. Hughes (Ed.), 15th Annual ARCOM Conference, 2, 15-17. Liverpool, UK.

Pavitt, T. C., \& Gibb, A.G.F. (2003). Interface management within construction: In Particular, Building Facade. Journal of Construction Engineering and Management, 129(1), 8. doi:10.1061/(ASCE)0733-9364(2003)129:1(8)

Pingtserng, H. (2004). Developing an activity-based knowledge management system for contractors. Automation in Construction, 13(6), 781-802. doi:10.1016/j.autcon.2004.05.003

Tzortzopoulos, P., Sexton, M., \& Cooper, R. (2005). Process models implementation in the construction industry: A literature synthesis. Engineering, Construction and Architectural Management, 12(5), 470-486.

Vaz, D., Al Bizri, S., \& Gray, C. (2008). The management of the design of modern curtain wall cladding systems. In ARCOM 24th Annual Conference (pp. 759-768). Cardiff, UK.

Voss, E., \& Overend, M. (2012). A tool that combines building information modeling and knowledge based engineering to assess Façade manufacturability. In ABS 2012, Graz.

Wix, J., \& Karlshoj, J. (2010). BuildingSMART: Information Delivery Manual Guide to Components and Development Methods.

Wynn. (2007). Model-based approaches to support process improvement in complex product development. University of Cambridge. 